patients receiving only conventional DMARDs therapy, treated and followed under T2T strategy recommendations and a MCM model.

Disclosure of Interest: None declared

DOI: 10.1136/annrheumdis-2017-eular.5592

\section{THU0173 LONG TERM SAFETY AND EFFICACY OF FILGOTINIB IN A PHASE 2B OPEN LABEL EXTENSION STUDY IN PATIENTS WITH RHEUMATOID ARTHRITIS: RESULTS UP TO 144 WEEKS}

R. Alten $^{1}$, R. Westhovens ${ }^{2}$, A. Kavanaugh ${ }^{3}$, M. Genovese ${ }^{4}$, K. Winthrop ${ }^{5}$, M. Greenwald ${ }^{6}$, L. Ponce ${ }^{7}$, F. Enriquez ${ }^{8}$, M. Stanislavchuk $^{9}$, M. Mazur $^{10}$ A. Spindler ${ }^{11}$, R. Cseuz ${ }^{12}$, N. Nikulenkova ${ }^{13}$, M. Glowacka-Kulesz ${ }^{14}$, I. Szombati ${ }^{15}$, A. Dudek ${ }^{16}$, L. Meuleners ${ }^{17}$, C. Tasset ${ }^{17}$, P. Harrison ${ }^{17}$, A. Van der Aa ${ }^{17} .{ }^{1}$ Schlosspark-Klinik, Berlin, Germany; ${ }^{2}$ University Hospitals, Leuven, Belgium; ${ }^{3}$ University of California, la Jolla; ${ }^{4}$ Stanford University School of Medicine, Palo Alto; ${ }^{5}$ Oregon Health and Science University, Portland; ${ }^{6}$ Desert Medical Advances, Palm Springs, United States; ${ }^{7}$ Cons. Priv., Temuco, Chile; ${ }^{8}$ Clinstile SA de CV, Col.Roma, Mexico; ${ }^{9}$ Vinnitsya Reg Clin Hosp, Vinnitsya, Ukraine; ${ }^{10} \mathrm{MSP}$ Inst. de Cardiologie, Chisinau, Moldova, Republic of; ${ }^{11}$ Centro Méd. Priv. Reum., Tucumau, Argentina; ${ }^{12}$ Revita Reumatológiai Kft, Budapest, Hungary; ${ }^{13}$ Vladimir Reg Clin Hosp, Shosse, Russian Federation; ${ }^{14}$ Silesiana Centrum Medyczne, Wroclawska, Poland; ${ }^{15}$ Qualiclinic Kft, Budapest, Hungary; ${ }^{16}$ AMED Medical Center, Warsaw, Poland; ${ }^{17}$ Galapagos NV, Mechelen, Belgium

Background: Filgotinib (GLPG0634, GS-6034) is an oral JAK1 selective inhibitor with a favorable safety and efficacy profile in two 24-week Phase $2 \mathrm{~b}$ studies as add-on to methotrexate (DARWIN 1) or as monotherapy (DARWIN 2) in patients with active rheumatoid arthritis (RA). Three daily doses were tested (50mg, $100 \mathrm{mg}$ or $200 \mathrm{mg}$ ) in comparison to placebo.

Objectives: To assess long term safety and efficacy of filgotinib $200 \mathrm{mg}$ daily in patients from the DARWIN 3 Phase 2 open-label extension study.

Methods: Patients who completed DARWIN 1 or 2 and enrolled in DARWIN 3 received filgotinib $200 \mathrm{mg}$ once daily or $100 \mathrm{mg}$ twice daily, depending on prior treatment assignment. The DARWIN 3 data cut off was when the last patient reached extension Week 60 . For safety, all data from the first intake of filgotinib in DARWIN 1/2/3 were analysed (up to 144 weeks).

Results: 877 patients participated in DARWIN 1 or 2, 790 completed and 739 entered DARWIN 3 from 22 countries ( $82 \%$ females, mean age $53 y$ ). 559 patients (75.6\%) completed Week 60, 9.3\% discontinued due to positive Quantiferon, $7.8 \%$ due to other adverse events, $6.8 \%$ for other reasons and $0.3 \%$ due to insufficient response. Overall exposure to filgotinib was 1314 patient-years (PYE). Treatment-emergent adverse events (157.7/100PYE), serious adverse events (5.3/100PYE) and serious infections (1.9/100PYE) occurred at similar rates compared to the core studies, however infections decreased on a percentage basis from $15 \%(109 / 739$, W0-12) to $5 \%(25 / 549$, W85-96). 16 cases of Herpes zoster were reported (1.2/100PYE), 6 cases of malignancy (excl. NMSC) (0.5/100PYE) and 1 case of MACE (0.1/100PYE). There was no active case of tuberculosis. Three fatalities were reported (0.2/100PYE). Mean change from baseline (CFB) at Week 96 and CTCAE toxicity grading in lab parameters of special interest are shown in table 1.

Table 1. Mean CFB at Week 96 and CTCAE toxicity grading of selected lab parameters

\begin{tabular}{lcc}
\hline & Mean CFB & CTCAE Grade 3-4 (\%) \\
\hline $\mathrm{Hb}$ & $+6.5 \mathrm{~g} / \mathrm{L}$ & 0.4 \\
Neutrophils & $-1.73 \mathrm{giga} / \mathrm{L}$ & 1 \\
Lymphocytes & $-0.19 \mathrm{giga} / \mathrm{L}$ & 2 \\
Creatinine & $+8.2 \mu \mathrm{mol} / \mathrm{L}$ & 0 \\
$\mathrm{ALT}$ & $+6.1 \mathrm{U} / \mathrm{L}$ & 0.4 \\
$\mathrm{LDL}$ & $+13 \%$ & - \\
$\mathrm{HDL}$ & $+23 \%$ & - \\
Tot chol/HDL & $-4 \%$ & - \\
NK cells & $-0.02 \mathrm{giga} / \mathrm{L}$ & - \\
\hline
\end{tabular}

Based on an observed case analysis 84\% (505/601), 65\% (389/601), 44\% (267/601) and 51\% (299/587) of patients reached ACR20, ACR50, ACR70 and DAS28(CRP) remission at Week 60 respectively.

Conclusions: With 1314 patient-years of exposure, the safety profile of filgotinib appears consistent with that of previously reported double-blind studies and the clinical response appears durable.

\section{References:}

[1] Westhovens R et al. Ann Rheum Dis 2016;0:1-11.

[2] Kavanaugh A et al. Ann Rheum Dis 2016:0:1-11.

Disclosure of Interest: R. Alten Grant/research support from: Galapagos, R. Westhovens Grant/research support from: Roche, Consultant for: Galapagos, Speakers bureau: BMS, A. Kavanaugh Consultant for: Galapagos, Pfizer, AbbVie, Amgen, Celgene, Janssen, Novartis, Eli Lilly, UCB, M. Genovese Grant/research support from: Abbvie, Eli Lilly, Pfizer, Astellas, Vertex, Consultant for: Galapagos, Gilead, Abbvie, Eli Lilly, Pfizer, Astellas, Vertex, K. Winthrop Grant/research support from: BMS, Pfizer, Consultant for: pfizer, BMS, lilly, Abbvie, Roche, UCB, Galapagos, Amgen, M. Greenwald Grant/research support from: Abbvie,Amgen, Bristol Myers Squibb, Celgene, Galapagos, Gilead, Lilly, Merck, Pfizer, UCB, Consultant for: Lilly, Pfizer, L. Ponce: None declared, F. Enriquez: None declared, M. Stanislavchuk: None declared, M. Mazur: None declared, A. Spindler: None declared, R. Cseuz: None declared, N. Nikulenkova: None declared, M. GlowackaKulesz: None declared, I. Szombati: None declared, A. Dudek: None declared, L. Meuleners Employee of: Galapagos NV, C. Tasset Employee of: Galapagos NV, P. Harrison Employee of: Galapagos NV, A. Van der Aa Employee of: Galapagos NV

DOI: 10.1136/annrheumdis-2017-eular.5460

\section{THU0174 DRUG RETENTION OF TOFACITINIB VERSUS BIOLOGIC ANTIRHEUMATIC AGENTS IN RHEUMATOID ARTHRITIS: OBSERVATIONAL DATA FROM THE SWISS SCQM REGISTRY}

A. Finckh $^{1}$, L. Herzog ${ }^{2}$, A. Scherer ${ }^{2}$, J. Dudler $^{3}$, B. Moeller ${ }^{4}$, A. Ciurea ${ }^{5}$, R. Mueller ${ }^{6}$, P. Hasler ${ }^{7}$, P. Exer ${ }^{8}$, I. von Muehlenen ${ }^{8}$, D. Kyburz ${ }^{9}$, C. Gabay ${ }^{1}$, P. Zufferey ${ }^{10}$ on behalf of the Physicians of the SCQM. ${ }^{1}$ HUG, Geneva; ${ }^{2}$ SCQM Foundation, Zurich; ${ }^{3}$ HFR, Fribourg; ${ }^{4}$ Inselspital, Bern; ${ }^{5}$ USZ, Zurich; ${ }^{6}$ KSSG, St Gallen; ${ }^{7}$ KSA, Aarau; ${ }^{8}$ Rheuma-Basel Practice; ${ }^{9}$ USB, Basel; ${ }^{10} \mathrm{CHUV}$,

Lausanne, Switzerland

Background: The oral Janus kinase inhibitor tofacitinib (Tofa) was licensed in Switzerland in 2013 for the treatment of moderate to severe rheumatoid arthritis (RA) patients having failed methotrexate. Besides Tofa, rheumatologists in Switzerland have the choice between 7 alternative bDMARDs licensed with similar indications, including 5 TNF inhibitors (TNFi) and 2 bDMARDs with other modes of action (OMA-bDMARDs).

Objectives: To compare the drug retention rate of three alternative treatment options licensed with a similar indications, namely Tofa, TNFi and OMA-bDMARDs, using data from the Swiss registry.

Methods: This is an observational cohort study within the Swiss Clinical Quality Management registry (SCQM). All therapies with Tofa, TNFi, and OMA-bDMARDs initiated in adult RA patients between August 1, 2013 and Dec 1, 2016 were considered. The exposure of interest was treatment with Tofa vs TNFi and vs OMA-bDMARDs (Abatacept or Tocilizumab). The primary outcome was drug retention defined as the time from initiation to discontinuation of treatment. We used Kaplan Meier curves to display drug retention and Cox proportional hazard models stratified by seropositivity to analyze the hazard for treatment discontinuation. We adjusted for potential confounders, including gender, age, disease duration, seropositivity, BMI, smoking status, DAS28-CRP and the total number of previous bDMARDs. We applied multiple imputation to account for missing baseline covariate data.

Results: A total of 1996 therapies were initiated during the study period (376 Tofa, $928 \mathrm{TNFi}, 692$ OMA-bDMARDs). Some differences in disease and treatment characteristics existed between the 3 groups, in particular TNFi tended to be used in patients with fewer previous bDMARDs experience, younger age and shorter disease duration. The crude overall drug retention was similar between the 3 three drug groups $(p=0.24)$ (Figure 1A). The adjusted analysis demonstrated a slightly higher hazard of drug discontinuation with TNFi compared to Tofa [HR 1.27 (95\% $\mathrm{Cl}: 1.02-1.57, \mathrm{p}=0.03)$ ], while no difference was observed for OMA-bDMARDs and Tofa [HR 1.03 (95\% Cl: $0.83-1.28, p=0.76)$ ] (Figure 1B). Complete case results were consistent with results using multiple imputation of baseline covariates. Other variables significantly associated with drug discontinuation were a higher number of previous bDMARDs $(p<0.001)$ and increasing BMI values $(p=0.03)$, while combination therapy with sDMARDs tended to decrease discontinuation $(p=0.08)$
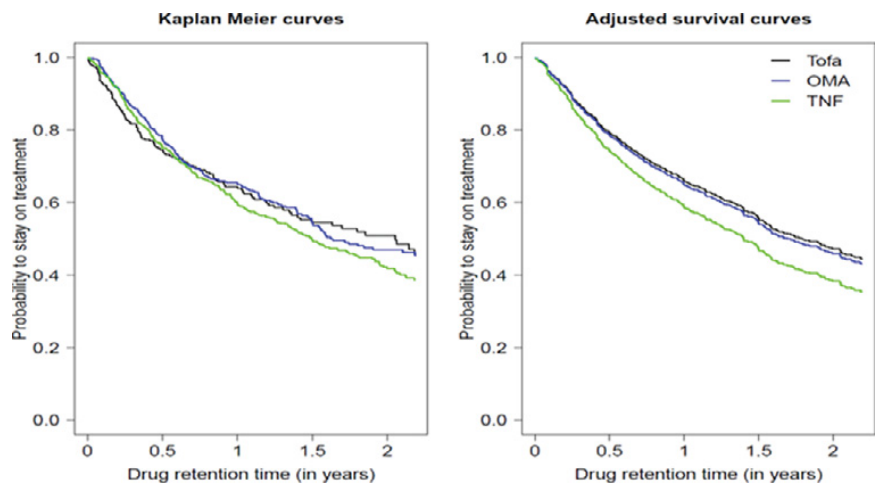

Conclusions: The results of this observational study suggest that Tofa is a valuable alternative to treatment options in RA, with Tofa drug retention at least comparable to other available bDMARDs.

Acknowledgements: Disclosure. Investigator Initiated Research grant supported by Pfizer.

Disclosure of Interest: A. Finckh Grant/research support from: BMS, Speakers bureau: Abbvie, BMS, Pfizer, Roche, UCB, L. Herzog: None declared, A. Scherer: None declared, J. Dudler: None declared, B. Moeller: None declared, A. Ciurea: None declared, R. Mueller: None declared, P. Hasler: None declared, P. Exer: None declared, I. von Muehlenen: None declared, D. Kyburz: None declared, C. Gabay: None declared, P. Zufferey: None declared

DOI: 10.1136/annrheumdis-2017-eular.6804 